\title{
Preface: advances in modelling photosynthetic processes in terrestrial plants
}

\author{
Nerea Ubierna ${ }^{1} \cdot$ Lucas A. Cernusak $^{2}$
}

Published online: 17 June 2019

(c) Springer Nature B.V. 2019

Photosynthesis converts solar energy into chemical bond energy by capturing $\mathrm{CO}_{2}$ from the atmosphere and incorporating it into organic molecules. It is a process central to the global carbon cycle, food and energy production, and indeed life on Earth. Understanding and modelling photosynthesis therefore has a large role to play in society's quest for a sustainable future. Models of photosynthesis are employed, for example, in predicting the impact of rising atmospheric $\mathrm{CO}_{2}$ on future climate and in efforts to develop crops that utilize resources more efficiently. In this Special Issue, we bring together a collection of papers aimed at improving models of photosynthesis and their parameterization for terrestrial plants.

Photosynthesis can be limited by both the stomatal and the mesophyll conductance to $\mathrm{CO}_{2}$ (Farquhar and Sharkey 1982; Flexas et al. 2012). An increase in the conductance of either one will allow $\mathrm{CO}_{2}$ to diffuse more readily from the atmosphere into the chloroplast stroma $\left(\mathrm{C}_{3}\right.$ species $)$ or into the mesophyll cells $\left(\mathrm{C}_{4}\right.$ species $)$, where carboxylation takes place. This Special Issue commences with a Critical Review by Ubierna et al. (2019) which addresses how the arrangement of chloroplasts and mitochondria within mesophyll cells of $\mathrm{C}_{3}$ species impacts the modelling of $\mathrm{CO}_{2}$ fluxes between the intercellular air space and the chloroplast stroma. Traditional photosynthesis and stable carbon isotope discrimination $\left(\Delta^{13} \mathrm{C}\right)$ models have assumed that all (photo) respired $\mathrm{CO}_{2}$ must cross the chloroplast before diffusing out of the leaf. In reality, all or part of the (photo)respired $\mathrm{CO}_{2}$ could diffuse through the cytosol without ever entering the chloroplast (Tholen et al. 2012; Farquhar and Busch 2017; Yin and Struik 2017). In the review, Ubierna et al. discuss

Nerea Ubierna

nerubierna@gmail.com

1 Research School of Biology, Australian National University, Acton, ACT 2601, Australia

2 College of Science and Engineering, James Cook University, Cairns, QLD, Australia photosynthesis models in conjunction with their treatment of the (photo)respiratory flux and present a new generalized $\Delta^{13} \mathrm{C}$ model applicable to the case where (photo)respired $\mathrm{CO}_{2}$ can diffuse both into the chloroplast and into the cytosol (Ubierna et al. 2019).

Subsequent papers in the Special Issue focus on addressing the diffusion resistance of the intercellular air space itself (Šantrůček et al. 2019), diurnal patterns of mesophyll conductance and the relation between this and water-use efficiency (Stangl et al. 2019), and variation in the temperature response of mesophyll conductance among genotypes of soybean, barley and sunflower (Shrestha et al. 2019). Stangl et al. (2019) and Shrestha et al. (2019) illustrate the potential of laser absorption spectroscopy for high-resolution measurements of leaf $\mathrm{CO}_{2}$ and water isotope exchange in field and laboratory settings, respectively. Stangl et al. (2019) used a cavity ring-down $\mathrm{CO}_{2}$ analyser coupled to a gas exchange system to derive diurnal patterns of mesophyll conductance for Pinus sylvestris trees growing in the field. Shrestha et al. (2019) coupled a tunable-diode laser absorption spectroscope, a cavity ring-down water isotope analyser and a gas exchange system to obtain combined measurements of carbon and oxygen isotope discrimination during photosynthesis. These data were used to separate total mesophyll conductance into wall and chloroplast components, which helped investigate the mechanisms behind the observed patterns in mesophyll conductance variation. Šantrůček et al. (2019) employed a novel technique looking at the carbon isotope composition of leaf cuticles on opposing sides of hypostomatous leaves to estimate the drawdown in $\mathrm{CO}_{2}$ concentration caused by the diffusion resistance of the intercellular air space across the leaf. Combined, these papers provide refinements to our understanding of the limitations of $\mathrm{CO}_{2}$ diffusion within leaves, and how these can be incorporated into existing models of photosynthesis. However, they also highlight how mesophyll conductance is a complex trait that remains poorly understood (Shrestha et al. 2019). 
The interaction between stomatal conductance and photosynthesis is central to the coordination of plant water use and plant carbon gain, which is often expressed as wateruse efficiency (Cernusak 2019). One of the features of this coordination that is still unclear is the mechanism or mechanisms through which stomatal behaviour and photosynthetic metabolism communicate to achieve coordination (Engineer et al. 2016). This Special Issue includes two papers that present advancements on knowledge of this topic: one via a model of stomatal movements based on the redox state of plastoquinone (Kromdijk et al. 2019), and the other using a new formulation of a dynamic model of $\mathrm{C}_{3}$ photosynthesis coupled with a hydro-mechanical model of stomatal behaviour (Bellasio 2019).

Empirical stomatal conductance models, such as the widely used Ball-Woodrow-Berry (BWB) model (Ball et al. 1986; Medlyn et al. 2011), assume a direct link between photosynthesis and light-induced stomatal movements. However, this is inconsistent with a recent hypothesis stating that guard cells might sense the redox state of the chloroplastic plastoquinone (PQ) pool (Busch 2014; Głowacka et al. 2018). Herein, Kromdijk et al. (2019) modified the BWB model to incorporate the putative causal relationship between PQ redox state and light-induced stomatal movements. Their modified model had a prediction accuracy similar to the original model, was simple enough to facilitate integration in models of greater scale, and the fitted parameters were less variable across a range of conditions. If the reduced variation in parameters can be shown to hold across a larger range of species and conditions, this can facilitate the integration of empirical stomatal models in ecosystem scale models.

Bellasio (2019) presents a process-based photosynthetic model for $\mathrm{C}_{3}$ photosynthesis that integrates and expands the functionalities of previously published dynamic models. Traditional steady-state photosynthesis models have limited functionality when investigating the response of photosynthesis to rapid variations in environmental drivers. For that reason, dynamic models are more appropriate; however, these models must trade-off complexity with practicality. The model of Bellasio (2019) is presented in a user-friendly format which can be run as a freely downloadable, standalone workbook in Microsoft ${ }^{\circledR}$ Excel $^{\circledR}$.

One of the foremost questions with respect to climate change is the extent to which increasing temperatures may stress vegetation and reduce photosynthesis rates in tropical forests (Cernusak et al. 2013). The final paper in the Special Issue explores temperature optima for photosynthesis and stomatal conductance in rainforest leaves and the extent to which this varies between sun and shade leaves (Slot et al. 2019). The authors find that there appears to be only a marginal potential for acclimation of the temperature response based on leaf microclimates, and that at supra-optimal temperatures carbon gain is largely constrained by stomatal conductance.

Almost 40 years after the publication of the landmark model of $\mathrm{C}_{3}$ photosynthesis by Farquhar, von Caemmerer and Berry (Farquhar et al. 1980), the modelling of photosynthesis remains an active field of research. Models have allowed the formulation and testing of new hypotheses, which have led to their refinement. Quoting Graham Farquhar, "one doesn't really understand something until one can describe it mathematically" (Farquhar et al. 2001). We encourage scientists to continue to strive for advances in the field of photosynthetic modelling, given that this work can provide a clearer understanding of the mechanics behind the most central process to life on Earth. We would like to express our thanks to all of the authors and reviewers who made this Special Issue possible via their contributions, and additionally to Terry M. Bricker, Editor in Chief of Photosynthesis Research for his encouragement, advice and assistance.

\section{References}

Ball JT, Woodrow IE, Berry JA (1986) A model predicting stomatal conductance and its contribution to the control of photosynthesis under different environmental conditions. In: Biggins J (ed) Progress in photosynthesis research. Springer, Providence, pp 221-224

Bellasio C (2019) A generalised dynamic model of leaf-level $\mathrm{C}_{3}$ photosynthesis combining light and dark reactions with stomatal behaviour. Photosynth Res. https://doi.org/10.1007/s11120-018-0601-1

Busch FA (2014) Opinion: the red-light response of stomatal movement is sensed by the redox state of the photosynthetic electron transport chain. Photosynth Res 119:131-140

Cernusak LA (2019) Gas exchange and water-use efficiency in plant canopies. Plant Biol. https://doi.org/10.1111/plb.12939

Cernusak LA, Winter K, Dalling JW, Holtum JAM, Jaramillo C, Körner C, Leakey ADB, Norby RJ, Poulter B, Turner BL, Wright SJ (2013) Tropical forest responses to increasing atmospheric $\mathrm{CO}_{2}$ : current knowledge and opportunities for future research. Funct Plant Biol 40:531-551

Engineer CB, Hashimoto-Sugimoto M, Negi J, Israelsson-Nordström M, Azoulay-Shemer T, Rappel W-J, Iba K, Schroeder JI (2016) $\mathrm{CO}_{2}$ sensing and $\mathrm{CO}_{2}$ regulation of stomatal conductance: advances and open questions. Trends Plant Sci 21(1):16-30

Farquhar GD, Busch FA (2017) Changes in the chloroplastic $\mathrm{CO}_{2}$ concentration explain much of the observed Kok effect: a model. New Phytol 214:570-584

Farquhar GD, Sharkey TD (1982) Stomatal conductance and photosynthesis. Annu Rev Plant Physiol 33:317-345

Farquhar GD, von Caemmerer S, Berry JA (1980) A biochemicalmodel of photosynthetic $\mathrm{CO}_{2}$ assimilation in leaves of $\mathrm{C}_{3}$ species. Planta 149(1):78-90

Farquhar GD, von Caemmerer S, Berry JA (2001) Models of photosynthesis. Plant Physiol 125:42-45

Flexas J, Barbour MM, Brendel O, Cabrera HM, Carriqui M, DiazEspejo A, Douthe C, Dreyer E, Ferrio JP, Gago J, Galle A, Galmes J, Kodama N, Medrano H, Niinemets U, Peguero-Pina JJ, Pou A, Ribas-Carbo M, Tomas M, Tosens T, Warren CR (2012) 
Mesophyll diffusion conductance to $\mathrm{CO}_{2}$ : an unappreciated central player in photosynthesis. Plant Sci 193:70-84

Głowacka K, Kromdijk J, Kucera K, Xie J, Cavanagh AP, Leonelli L, Leakey ADB, Ort DR, Niyogi KK, Long SP (2018) Photosystem II Subunit $S$ overexpression increases the efficiency of water use in a field-grown crop. Nat commun 9:868

Kromdijk J, Głowacka K, Long SP (2019) Predicting light-induced stomatal movements based on the redox state of plastoquinone: theory and validation. Photosynth Res. https://doi.org/10.1007/ s11120-019-00632-x

Medlyn BE, Duursma RA, Eamus D, Ellsworth DS, Prentice C, Barton CVM, Crous KY, De Angelis P, Freeman M, Wingate L (2011) Reconciling the optimal and empirical approaches to modelling stomatal conductance. Glob Change Biol 17:2134-2144

Šantrůček J, Schreiber L, Macková J, Vráblová M, Květoň J, Macek P, Neuwirthová J (2019) Partitioning of mesophyll conductance for $\mathrm{CO}_{2}$ into intercellular and cellular components using carbon isotope composition of cuticles from opposite leaf sides. Photosynth Res. https://doi.org/10.1007/s11120-019-00628-7

Shrestha A, Song X, Barbour MM (2019) The temperature response of mesophyll conductance, and its component conductances, varies between species and genotypes. Photosynth Res. https://doi. org/10.1007/s11120-019-00622-z

Slot M, Krause GH, Krause B, Hernández GG, Winter K (2019) Photosynthetic heat tolerance of shade and sun leaves of three tropical tree species. Photosynth Res. https://doi.org/10.1007/ s11120-018-0563-3

Stangl ZR, Tarvainen L, Wallin G, Ubierna N, Räntfors M, Marshall JD (2019) Diurnal variation in mesophyll conductance and its influence on modelled water use efficiency in a mature boreal Pinus sylvestris stand. Photosynth Res. https://doi.org/10.1007/ s11120-019-00642-9

Tholen D, Ethier G, Genty B, Pepin S, Zhu XG (2012) Variable mesophyll conductance revisited. Theoretical background and experimental implications. Plant, Cell Environ 35:2087-2103

Ubierna N, Cernusak LA, Holloway-Phillips M, Busch FA, Cousins AB, Farquhar GD (2019) Critical review: incorporating the arrangement of mitochondria and chloroplasts into models of photosynthesis and carbon isotope discrimination. Photosynth Res. https://doi.org/10.1007/s11120-019-00635-8

Yin X, Struik PC (2017) Simple generalisation of a mesophyll resistance model for various intracellular arrangements of chloroplasts and mitochondria in $\mathrm{C}_{3}$ leaves. Photosynth Res 132:211-220

Publisher's Note Springer Nature remains neutral with regard to jurisdictional claims in published maps and institutional affiliations. 